\title{
ANALISIS PENGARUH KINERJA KARYAWAN PT JASA MARGA (Persero) Tbk CABANG JAGORAWI
}

\author{
Nazwirman, Syamsu Alang, Agung Prianggodo \\ Universitas YARSI \\ Email:nazwir10@gmail.com
}

\begin{abstract}
The purpose of this study was to determine whether there is influence between work discipline, organizational culture on employee performance either partially or jointly in PT Jasa Marga (Persero) Tbk, Branch Jagorawi. Results of analysis that Work Discipline positive effect on employee performance, with a very strong degree of correlation values. influence the value of the $(\mathrm{R})$ of 0.871 , the contribution of the coefficient of determination $\left(\mathrm{R}^{2}\right)$ of 0.759 or $75.9 \%$. Organizational culture has a positive effect on employee performance, with a very strong degree of correlation values. influence the value of the $(\mathrm{R})$ of 0.915 , the contribution of the coefficient of determination $\left(\mathrm{R}^{2}\right)$ of 0.838 or $83.8 \%$. And Discipline of Work and Organisational Culture jointly have a positive influence on employee performance, with a very strong degree of correlation values. influence the value of the $(\mathrm{R})$ of 0.920 , the contribution of the coefficient of determination $\left(\mathrm{R}^{2}\right)$ of 0.847 or $84.7 \%$ indicates the significance of the effect given by the Discipline of Work and Organizational Culture on Employee Performance. ANOVA analysis showed that the obtained value obtained $F_{\text {value }}$ of 283.961 greater value to $F_{\text {table }}$ 3.940 at alpha $(\alpha) 5 \%=(267.551>3.940)$ means there is a rejection of $\mathrm{H}_{0}$. It means that the variable labor discipline and organizational culture together significantly affect employee performance variables, and there is a very strong influence of the value stated.
\end{abstract}

Keywords: Discipline Work, Organizational Culture, Performance

\begin{abstract}
Abstrak: Tujuan dari penelitian ini adalah untuk mengetahui apakah terdapat pengaruh antara disiplin kerja, budaya organisasi terhadap kinerja karyawan baik parsial maupun bersama-sama di PT Jasa Marga (Persero) Tbk, Cabang Jagorawi. Hasil analisis bahwa Disiplin Kerja berpengaruh positif terhadap Kinerja Karyawan, dengan nilai tingkat hubungan sangat kuat. nilai pengaruhnya yakni (R) sebesar 0,871 , kontribusi koefisien determinasi $\left(\mathrm{R}^{2}\right)$ sebesar 0,759 atau $75,9 \%$. Budaya Organisasi berpengaruh positif terhadap Kinerja Karyawan, dengan nilai tingkat hubungan sangat kuat. nilai pengaruhnya yakni $(\mathrm{R})$ sebesar 0,915 , kontribusi koefisien determinasi $\left(\mathrm{R}^{2}\right)$ sebesar 0,838 atau 83,8\%. Dan Disiplin Kerja dan Budaya Organisasi secara bersama-sama memiliki pengaruh positif terhadap Kinerja Karyawan, dengan nilai tingkat hubungan sangat kuat. nilai pengaruhnya yakni $(R)$ sebesar 0,920 , kontribusi koefisien determinasi $\left(R^{2}\right)$ sebesar 0,847 atau 84,7\% menunjukkan pengaruh secara signifikansi yang diberikan oleh Disiplin Kerja dan Budaya Organisasi terhadap Kinerja Karyawan. Analisis Anova didapatkan nilai yang

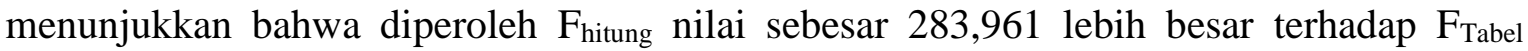
3,940 pada alpha $(\alpha) 5 \%=(267,551>3,940)$ berarti terjadi penolakan terhadap $\mathrm{H}_{0}$. Artinya variabel disiplin kerja dan budaya organisasi secara bersama-sama mempengaruhi secara signifikan terhadap variabel kinerja karyawan, dan terdapat pengaruh nilainya dinyatakan sangat kuat.
\end{abstract}

Kata Kunci: Disiplin Kerja, Budaya Organisasi, Kinerja 


\section{PENDAHULUAN}

Salah satu unsur penting dalam perubahan (change) ialah peran sumber daya manusia. keadaan ini mendorong pihak manajemen perusahaan terus mengupayakan penyempurnaan berbagai sistem dalam pengelolaan sumber daya manusia secara luas. Salah satu bentuk nyata adalah disiplin didalam suatu organisasi dapt meningkatkan produktivitas dan efisiensi perusahaan. Sekaligus dapat mendorong keharmonisan dan kerjasama antara karyawan serta bertindak sebagai pendorong semangat bagi karyawan (Chirasha, 2013). Manajemen disiplin kerja masih menjadi masalah utama dalam hubungan karyawan, dan merupakan salah satu sumber yang paling dilihat konflik di tempat kerja.

Faktor lain adalah budaya suatu organisasi terdiri dari adat tidak tertulis, perilaku dan keyakinan yang menentukan "aturan main" untuk pengambilan keputusan, struktur dan kekuasaan. Ini didasarkan pada sejarah dan tradisi organisasi yang digabungan dengan nilai-nilai kepemimpinan. Akibatnya, budaya ini menentukan cara melakukan usahan dan taktik untuk kelangsungan hidup (Dave H. dan Jeanne Urich, 2011). Budaya organisasi terbentuk diawali dengan suatu proses yang secara keseluruhan akan bermuara kepada tujuan awal, yakni mereka mempunyai suatu visi (penglihatan) mengenai bagaimana seharusnya organisasi itu dan mereka tidak terhambat oleh kebiasaan atau ideologi sebelumnya.

Pada akhirnya melalui pembentukan budaya organisasi yang kuat diharapkan berdampak positif terhadap kinerja karyawan dalam menjalankan tugas dan tanggung jawabnya sebab mereka terpilih melalui serangkaian seleksi lewat perilaku dan konsistensi nilai-nilai yang ditanamkan dalam visi dan misi organisasi. Dalam penilaian kinerja terhadap karyawan didasarkan pada job description yang telah disusun oleh organisasi. Demikian pula penilaian kinerja di lingkungan karyawan PT. Jasa Marga (Persero) Tbk. Penilaian kinerja karyawan perusahaan dilaksanakan menggunakan daftar penilaian pelaksanaan pekerjaan dengan unsur-unsur yang terdapat di dalamnya, meliputi: kesetiaan, prestasi kerja, kejujuran, kedisiplinan, kerjasama, kepribadian, prakarsa/inisiatif, kecakapan, tanggung jawab, dan kepemimpinan. Gambaran perusahaan tersebut atas disiplin kerja, budaya organisasi dan kinerja dapat dilihat hasil rekapitulasi evaluasi absensi dan evaluasi prestasi kerja karyawan (Tabel 1).

Tabel 1. Rekapitulasi Evaluasi Absensi dan Evaluasi Kinerja Karyawan PT. Jasa Marga (Persero) Tbk- Cabang Jagorawi Periode Tahun 2012-2014

\begin{tabular}{|c|c|c|c|c|c|c|c|c|c|}
\hline \multirow{2}{*}{ Th } & \multicolumn{4}{|c|}{ Evaluasi Absensi Karyawan } & \multicolumn{5}{|c|}{ Evaluasi Kinerja Karyawan } \\
\hline & $\begin{array}{l}\text { Telat } \\
\text { (Menit) }\end{array}$ & $\begin{array}{c}\text { Ijin } \\
\text { (Hari) }\end{array}$ & $\begin{array}{c}\text { Alpa } \\
\text { (Hari) }\end{array}$ & $\begin{array}{c}\text { Sakit } \\
\text { (Hari) }\end{array}$ & Baik & Rata-rata & Kurang & $\begin{array}{l}\text { Sangat } \\
\text { Kurang }\end{array}$ & Ket. \\
\hline 2012 & 41.093 & 325 & 521 & 158 & $70,947 \%$ & $71296,35 \%$ & $202,706 \%$ & - & $\begin{array}{l}\text { Jumlah } \\
\text { Karyawan } \\
739 \text { orang }\end{array}$ \\
\hline 2013 & 72.917 & 474 & 504 & 2.418 & $437,665 \%$ & $50990,73 \%$ & $91,604 \%$ & - & $\begin{array}{l}\text { Jumlah } \\
\text { karyawan } \\
561 \text { orang }\end{array}$ \\
\hline 2014 & 96.947 & 343 & 346 & 2.015 & $548,048 \%$ & $60389,87 \%$ & $131,937 \%$ & $10,149 \%$ & $\begin{array}{l}\text { Jumlah } \\
\text { karyawan } \\
671\end{array}$ \\
\hline
\end{tabular}

Sumber: PT Jasa marga (Persero) Tbk-Cab Jagorawi (2015) 
Tabel 1 terlihat disiplin kerja karyawan masih rendah hal tersebut dibuktikan berdasarkan evaluasi absensi, jumlah telat/keterlambatan dalam masuk jam kerja, mangkir mengalami peningkatan setiap tahun. Hal tersebut menunjukkan kesadaran atas disiplin kerja dan menjalankan tugas belum baik Akibatnya berdampak terhadap terganggunya operasional dilapangan serta mengganggu terhadap kinerja individu lainnya secara langsung.

Evaluasi kinerja karyawan terlihat bahwa prosentase prestasi kategori (baik) masih sangat rendah yang menunjukkan angka hanya mencapai rata-rata 5,55 \% per 3 tahun, kategori (kurang) dan (sangat kurang) rata-rata 2,13\% per 3 tahun dan sisanya dengan kategori prestasi kerja (rata-rata/standard) mencapai $92,32 \%$ per 3 tahun, data tersebut menunjukkan tidak kuat keinginan karyawan untuk meningkatkan kinerjanya mencapai kategori baik atau bahkan jika dimungkinkan menjadi sangat baik.

Tujuan penelitian ini menganalisa dan menguji uji kinerja karyawan PT Jasa Marga (Persero) Tbk, Cabang Jagorawi ditinjau dari variabel disiplin kerja dan budaya organisasi.

\section{KAJIAN TEORI}

Disiplin Kerja. Disiplin merupakan tindakan manajer untuk mendorong anggota organisasi memenuhi tuntutan berbagai ketentuan tersebut. Dengan kata lain, pendisiplinan karyawan adalah suatu bentuk pelatihan yang berusaha memperbaiki dan membentuk pengetahuan, sikap dan perilaku karyawan sehingga karyawan tersebut secara suka rela berusaha bekerja secara kooperatif dang karyawan lain sehingga meningkatkan prestasi kerjanaya (Siagian, 2008). Hasibuan (2007) mengatakan kedisiplinan merupakan kesadaran dan kesediaan seorang menaati semua peraturan perusahaan dan norma-norma sosial yang berlaku. Selanjutnya disiplin sebagai kondisi dalam organisasi dimana karyawan berperilaku sesuai dengan organisasi aturan dan standar perilaku yang dapat diterima.

Disiplin sangat penting untuk suasana industrial yang sehat dan pencapaian tujuan organisasi. Disiplin kerja dalam suatu perusahaan atau organisasi merupakan bagian penting untuk mencapai kinerja pegawai untuk pencapaian tujuan yang diinginkan oleh suatu organisasi/perusahaan. Kedisiplinan yang ditanamkan pegawai akan sangat mempengaruhi kesungguhan pegawai dalam bekerja (Monnapa, 2000). Oleh karena itu, perlu upaya pemimpin untuk membuat karyawan dalam bekerja secara disiplin dan pemimpin tersebut juga harus dapat menunjukkan cara yang paling baik dan membantu karyawan bertindak disiplin dalam menyelesaikan tugas/pekerjaan sehari-harinya. Hasil temuan yang dilakukan (Legowo dkk, 2012), menunjukkan bahwa disiplin kerja berpengaruh positif terhadap kinerja karyawan. Atas dasar tesebut hipotesis penelitian ini: H1: Terdapat pengaruh signifikan Disiplin Kerja $\left(\mathrm{X}_{1}\right)$ terhadap Kinerja Karyawan (Y).

Budaya Organisasi. Budaya adalah seperangkat kebiasaan, nilai-nilai, norma-norma dan keyakinan yang mempengaruhi pada suatu organisasi (Khorshidi 2008.). Budaya organisasi merupakan kombinasi dari harapan organisasi, pengalaman, filsafat dan nilainilai (Nazir dan Shazia, 2015). Budaya organisasi terdiri dari adat tidak tertulis, perilaku dan keyakinan yang menentukan "aturan main" untuk pengambilan keputusan, struktur dan kekuasaan. Ini didasarkan pada sejarah dan gabungan tradisi organisasi dengan nilai- 
nilai kepemimpinan bersama (Jen, 2007). Akibatnya, budaya menentukan cara melakukan bisnis dan taktik untuk kelangsungan hidup organisasi (Dave H. dan Jeanne Urich 2011).

Teori tentang budaya organisasi biasanya memiliki set pemikiran tentang perusahaan secara keseluruhan yang berbeda, seperti etika, keuntungan, atau filantropi (Wairimu, 2014). Schein (1996) menyatakan bahwa budaya organisasi adalah "A pattern of shared basic assumptions that the group learned as it solved its problems of external adaptation and internal integration, that has worked well enough to be considered valid and, therefore, to be taught to new members as the correct way to preceive, think, and feel it relation to these problems. Pola asumsi-asumsi dasar yang merupakan bentukan, penemuan, atau pengembangan oleh sesuatu kelompok dalam proses mengatasi permasalahan adaptasi eksternal, maupun integrasi internal yang telah bekerja cukup baik, sehingga dianggap cukup berharga dan karenanya juga diajarkan kepada para anggota baru sebagai cara yang benar dalam memandang, berpikir dan merasakan tentang masalahmasalah yang dihadapinya". Ada dua faktor utama yang menentukan kekuatan budaya organisasi: Kesamaan dan Intensitas. Kesamaan berarti sejauh mana organisasi anggota memiliki nilai-nilai inti yang sama. Intensitas adalah tingkat komitmen anggota organisasi dengan nilai-nilai inti (Syirodj dan Aurik Gustomo, 2014).

Budaya organisasi mempunyai dua tingkatan yang berbeda dilihat dari sisi kejelasan dan ketahanan organisasi terhadap perubahan. Pada tingkatan yang lebih dalam dan kurang terlihat, budaya organisasi merujuk pada nilai-nilai yang dianut bersama oleh orang dalam kelompok dan cenderung bertahan sepanjang waktu bahkan meskipun anggota kelompok sudah berubah. Pada tingkatan ini budaya bisa sangat sukar berubah, sebagian karena anggota kelompok sering tidak sadar akan banyaknya nilai yang mengikat mereka bersama.

Budaya organisasi mengacu ke sistem makna bersama yang dianut oleh anggota anggota yang membedakan organisasi itu dari organisasi - organisasi lain (Robbins, 2001). Budaya suatu organisasi dibangun dan dipertahankan bedasarkan budaya asli yang diturunkan dari filsafat pendirinya. Terbentuknya budaya organisasi (Gambar 1):

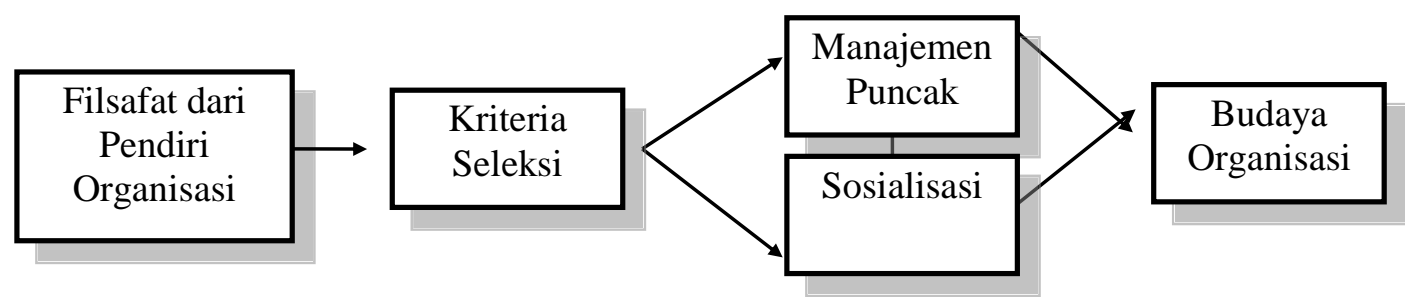

Gambar 1. Proses Terbentuknya Budaya Organisasi

Sumber : Stephen P. Robbins (2001 : 262)

Umumnya percaya bahwa budaya organisasi memiliki dampak yang besar pada kinerja organisasi (Nongo. D dam Ikyanyon, 2012). Selanjutnya ada dimensi lain dari budaya organisasi yang mungkin memainkan peran dalam kinerja karyawan dalam organisasi. Hasil penelitian juga telah menunjukkan bahwa jika karyawan memiliki norma-norma dan nilai-nilai organisasi yang sama maka ini akan meningkatkan kinerja karyawan untuk mencapai tujuan organisasi secara menyeluruh. Budaya organisasi dan hubungan kinerja telah diteliti oleh peneliti (Hendry et al., 2012; Ogbonna dan Harris, 2000; Rousseau, 1990). Budaya organisasi memiliki hubungan positif yang signifikan 
dengan praktek manajemen kinerja (Mujeeb et al., 2011; Wairamu, 2014; Awad dan Al Yahya, 2013). Atas dasar tesebut hipotesis yang diusulkan:

H2: Terdapat pengaruh signifikan Budaya Organisasi $\left(\mathrm{X}_{2}\right)$ terhadap Kinerja Karyawan (Y).

Kinerja Karyawan. Prestasi yang karyawan memenuhi misi organisasi di tempat kerja disebut dengan Kinerja (Awad dan Al Yahya, 2006). Hameed dan Waheed (2011) menyatakan bahwa kinerja karyawan pada akhirnya akan mempengaruhi efektivitas organisasi. Kinerja karyawan adalah seseorang yang mengeksekusi tugas dan pekerjaan dengan tanggungjawab (Agrawal, 2013). Dapat disimpulkan bahwa kinerja karyawan adalah hasil keluaran dari bagaimana karyawan berperilaku dalam suatu organisasi.

Kinerja organisasi sebagai kemampuan organisasi untuk mencapai tujuannya dengan menggunakan sumber daya secara efisien dan efektif (Daft, 2000). Hal ini didukung oleh Blanchard dan Zigami (1985) yang menegaskan bahwa seberapa baik manajer mengelola untuk bisnis tergantung pada seberapa baik mereka mengelola karyawan..

Kinerja merupakan hasil kerja yang dicapai seseorang karyawan terhadap pelaksanaan tugas perkerjaan yang dinilai berdasarkan pada kriteria atau standar penilaian tertentu. Istilah kinerja sering digunakan untuk menyebut tingkat keberhasilan individu atau kelompok dalam waktu tertentu. (Wirawan, 2009).

Pengukuran kinerja merupakan proses mencatat dan mengukur pencapaian pelaksanaan kegiatan dalam arah mencapai misi melalui hasil-hasil yang ditampilkan berupa produk, jasa, ataupun suatu. Dalam pelaksanaan penilaian kinerja karyawan harus jelas unsur-unsur yang akan dinilai (Hasibuan, 2007:95), yaitu: (1) Kesetiaan; diukur terhadap pekerjaan,jabatan, organisasi, kesetiaan ini dicerminkan oleh kesetiaan karyawan menjaga dan membela organisasi didalam maupun pekerjaannya; (2) Prestasi kerja; menilai hasil kerja baik kualitas maupun kuantitasnya. Bentuk penilaian yang ada dibuat dengan tujuan agar kinerja yang dihasilkan oleh karyawan dapat diukur dengan jelas;(3) Kejujuran; melaksanakn tugasnya, memenuhi perjanjian baik bagi karyawan sendiri maupun terhadap orang lain;(4) Kedisiplinan; Penilai menilai kedisplinan karyawan dalam memenuhi peraturan yang ada, mengerjakan pekerjaan sesuai dengan instruksi yang diberikan kepadanya;(5) Kerja sama; kemampuan karyawan untuk memimpin, mempengaruhi, mempunyai kepribadian yang kuat, dihormati, berwibawa dan dapat memotivasi orang lain atau bawahan untuk bekerja secara efektif; (6) Kepribadian; sikap prilaku, kesopanan, periang, disukai, memberikan kesan menyenangkan, memperhatikan sikap yang baik, serta penampilan simpati dan wajar; (7) Inisiatif; Kemampuan berfikir yang orisinal dan berdasarkan inisiatif sendiri untuk menganalisis, menilai, menciptakan, memberikan alasan, membuat kesimpulan dan menyelesaikan permasalahan yang dihadapi; (8) Kecakapan; menyelaraskan elemen-elemen yang semuanya terlibat dalam situasi manajemen. Elemen-elemen yang dimaksud adalah seluruh karyawan yang ada dalam perusahaan, baik dari level atau sampai dengan level bawah; (9) Tanggung jawab; kemampuan dalam mempertanggung jawabkan kebijaksanaannya, pekerjaan dan hasil kerjanya, sarana dan prasarana yang dipergunakan, serta prilaku kerjanya.

Dari hasil penelitian Schein (1989) memperlihatkan bahwa para pekerja akan merasa lebih puas dan memegang teguh komitmennya jika nilai-nilai mereka sesuai dengan nilainilai perusahaan. Budaya organisasi yang kondusif sangat penting untuk mendorong tingkat kinerja karyawan yang paling produktif. Budaya yang kuat meningkatkan 
komitmen, antusiasme, dan loyalitas anggota terhadap organisasi serta mempengaruhi individu-individu dan proses organisasi. Budaya dalam organisasi memunculkan tekanan pada orang-orang dalam organisasi untuk berfikir dan bertindak dengan cara yang konsisten dengan budaya yang ada, sehingga pada akhirnya dapat menghasilkan performansi kerja (kinerja) yang optimal bagi individu tersebut serta organisasi secara keseluruhan. Ditegakannya disiplin maka dapat mengatasi masalah kinerja yang buruk dan memperkuat pengaruh prilaku kerja pegawai dalam kelompok atau organisasi. Apabila disiplin dapat dilaksanakan dengan baik serta tidak menunda waktu maka masalah kinerja tidak dibiarkan menjadi parah, dan kemungkinan masalah yang terjadi dapat diatasi secara tepat dan mudah. Dalam banyak studi menunjukkan bahwa ada hubungan yang signifikan antara budaya organisasi dan kinerja karyawan, jika karyawan memiliki persepsi yang sama maka mereka akan lebih kooperatif dengan satu sama lain untuk mencapai tujuan mereka (Eric, 2010). Atas dasar tesebut hipotesis yang diusulkan:

H3: Terdapat pengaruh signifikan Disiplin Kerja $\left(\mathrm{X}_{1}\right)$ dan Budaya Organisasi $\left(\mathrm{X}_{2}\right)$ secara bersama-sama terhadap Kinerja Karyawan (Y).

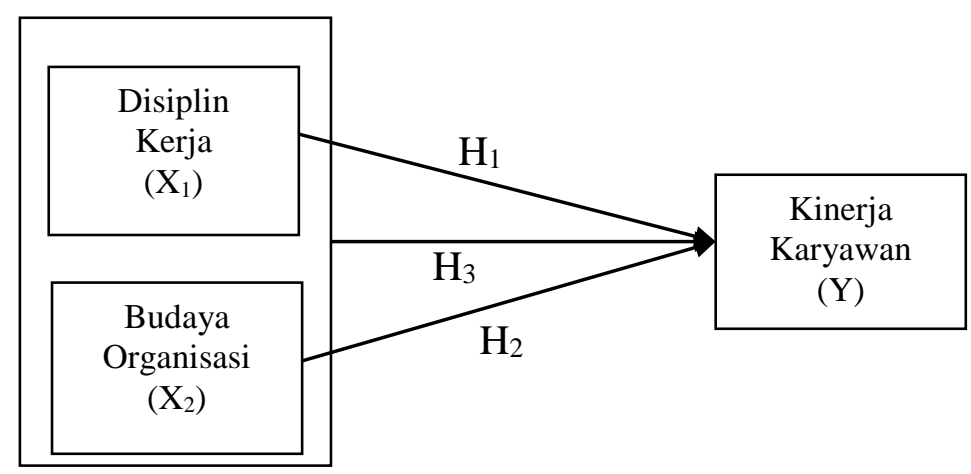

Gambar 2. Model Penelitian

\section{METODE}

Metode penelitian ini adalah metode kuantitatif dengan pendekatan korelasional. Penelitian ini bersifat asosiatif (Causal Research). Tujuannya untuk melihat pengaruh antara variabel-variabel yang diteliti, yaitu Disiplin Kerja dan Budaya Organisasi terhadap Kinerja Karyawan pada PT. Jasa Marga (Persero) Tbk, Cabang Jagorawi-Jakarta. Skala pengukuran menggunakan Likert dengan rentang lima skala 1 (sangat tidak setuju) sampai 5 (sangat setuju).

Populasi keseluruhan dari unit yang akan dianalisis berjumlah 648 orang. Populasi karyawan tersebut terdiri atas yang menduduki jabatan menurut jenjang jabatan Direksi sampai dengan Staf. Ukuran sampel diambil dari populasi dengan menggunakan rumus yamane (Slovin, 1990). Besarnya sampel pada setiap populasi yang akan diteliti, dengan cara stratifikasi random sampling, sebanyak 100 sampel. Analisis menggunakan perangkat lunak SPSS Versi 22.

\section{HASIL DAN PEMBAHASAN}


Uji Validitas dan Reliabilitas. Pada tingkat kepercayaan (valid) 95\%., hasil pernyataan seluruhnya dinyatakan valid Tabel 2.

Tabel 2. Explore hasil Uji Case Processing Summary

\begin{tabular}{lcccccc}
\hline & \multicolumn{6}{c}{ Cases } \\
\cline { 2 - 7 } & $\mathrm{N}$ & Percent & $\mathrm{N}$ & Percent & $\mathrm{N}$ & Percent \\
\hline & 100 & $100.0 \%$ & 0 & $.0 \%$ & 100 & $100.0 \%$ \\
Disiplin Kerja & 100 & $100.0 \%$ & 0 & $.0 \%$ & 100 & $100.0 \%$ \\
Budaya Organisasi & 100 & $100.0 \%$ & 0 & $.0 \%$ & 100 & $100.0 \%$ \\
Kinerja Karyawan & 100
\end{tabular}

Sumber: Hasil olahan SPSS V 22

Sedangkan hasil uji Reliabilitas (kehandalan) terhadap Varibel yang diteliti dapat di lihat Tabel 3

Tabel 3. Reliability

\begin{tabular}{lccc}
\multicolumn{1}{c}{ Variabel } & $\begin{array}{c}\text { Cronbach's } \\
\text { Alpha }\end{array}$ & $\begin{array}{c}\text { Cronbach's Alpha Based on } \\
\text { Standardized Items }\end{array}$ & N of Items \\
Disiplin Kerja $\left(\mathrm{X}_{1}\right)$ & 0.926 & 0.934 & 10 \\
Budaya Organisasi $\left(\mathrm{X}_{2}\right)$ & 0.922 & 0.932 & 10 \\
Kinerja Karyawan $(\mathrm{Y})$ & 0.930 & 0.940 & 12 \\
Sumber: Hasil olahan SPSS V 22 & & &
\end{tabular}

Tabel 3 menunjukan nilai Alpha Cronbach's masing-masing variabel lebih besar 0,7. Dengan demikian dapat nilai variabel seluruhnya reliabel.

Pengujian Hipotesis. Disiplin Kerja Terhadap Kinerja Karyawan. Hasil analisis regresi linier sederhana antara disiplin kerja terhadap Kinerja Karyawan, menghasilkan (tabel 4) $\mathrm{Y}=13,670+0,845\left(\mathrm{X}_{1}\right)$.

Tabel 4. Hasil uji koefisien Regresi $\mathrm{X}_{1}$ Terhadap $\mathrm{Y}$

\section{Coefficients $^{\mathrm{a}}$}

\begin{tabular}{|c|c|c|c|c|c|c|}
\hline \multirow[b]{2}{*}{ Model } & & \multicolumn{2}{|c|}{ Unstandardized Coefficients } & $\begin{array}{l}\text { Standardized } \\
\text { Coefficients }\end{array}$ & \multirow[t]{2}{*}{$\mathrm{T}$} & \multirow[t]{2}{*}{ Sig. } \\
\hline & & $\mathrm{B}$ & Std. Error & Beta & & \\
\hline \multirow[t]{2}{*}{1} & (Constant) & 13.670 & 3.990 & & 3.426 & 0.001 \\
\hline & Disiplin Kerja & .845 & .048 & 0.871 & 17.589 & 0.000 \\
\hline
\end{tabular}

a. Dependent Variable: Kinerja_Karyawan

Nilai t table pada alpha 5\%, df $1=99-1$ adalah 1.671

Nilai $r$ table pada alpha $5 \%, \mathrm{~N}=100$ adalah 0.195

Tabel 4 Nilai konstanta sebesar 13,670 menyatakan bahwa jika tidak ada disiplin kerja, maka kinerja karyawan sebesar 13,670. Nilai koefisien sebesar 0,845 menunjukkan bahwa penambahan nilai disiplin kerja akan menaikkan nilai kinerja karyawan sebesar 
0,845. Begitupula sebaliknya menurunkan nilai disiplin kerja akan menurunkan nilai kinerja karyawan sebesar 0,845. Sedangkan hasil $t_{\text {hitung }}$ Disiplin Kerja $\left(X_{1}\right) 3,426>t_{\text {tabel }}$ 1,9845, menunjukkan $\mathrm{H}_{0}$ ditolak. Dengan demikian dapat disimpulkan bahwa variabel disiplin kerja mempengaruhi terhadap kinerja karyawan secara signifikan.

Analisis varian dengan memperhatikan signifikan uji $\mathrm{F}$ regresi pengaruh disiplin kerja $\left(\mathrm{X}_{1}\right)$ terhadap kinerja karyawan signifikan. Hal ini dari nilai $F_{\text {hitung }}$ yang nilainya sebesar 309.372 Sedangkan nilai $F_{\text {tabel }}$ pada alpha ( $\alpha$ ) 5\% sebesar 3,940. Sehingga dapat dipaparkan bahwa nilai $F_{\text {hitung }}$ lebih besar dari $F_{\text {tabel, dimana }}(309.372>3,940)$ yang berarti terjadi penolakan terhadap $\mathrm{H}_{0}$. Artinya variabel disiplin kerja mempengaruhi secara signifikan terhadap variabel kinerja karyawan, dan terdapat pengaruh nilainya dinyatakan sangat kuat.

Budaya Organisasi Terhadap Kinerja Karyawan. Hasil analisis regresi linier sederhana antara budaya organisasi terhadap kinerja karyawan, menghasilkan $\mathrm{Y}=11,335+0,871$ $\left(\mathrm{X}_{2}\right)$

Tabel 5. Hasil uji koefisien Regresi $X_{2}$ Terhadap $Y$

\section{Coefficients $^{\mathrm{a}}$}

\begin{tabular}{rlrccrrr}
\hline & & \multicolumn{2}{c}{ Unstandardized Coefficients } & \multicolumn{2}{c}{$\begin{array}{c}\text { Standardized } \\
\text { Coefficients }\end{array}$} & \multirow{2}{*}{ T } & \multirow{2}{*}{ Sig. } \\
\cline { 3 - 5 } & Model & \multicolumn{1}{c}{$\mathrm{B}$} & Std. Error & Beta & & \\
\hline 1 & (Constant) & 11.335 & 3.221 & & 3.519 & 0.001 \\
& Budaya & .871 & 0.039 & 0.915 & 22.521 & 0.000 \\
Organisasi & & & & &
\end{tabular}

a. Dependent Variable: Kinerja_Karyawan

Nilai t table pada alpha 5\%, df $1=99-1$ adalah 1.671

Nilai $r$ table pada alpha 5\%, N=100 adalah 0.195

Tabel 5 hasil analisis antara budaya organisasi $\left(\mathrm{X}_{2}\right)$ terhadap kinerja karyawan $(\mathrm{Y})$, Nilai konstanta sebesar 11,335 menyatakan bahwa jika tidak ada budaya organisasi maka kinerja karyawan sebesar 11,335. Nilai koefisien sebesar 0,871 menunjukkan bahwa penambahan nilai budaya organisasi akan menaikkan nilai kinerja karyawan sebesar 0,871 . Begitupula sebaliknya menurunkan nilai budaya organisasi akan menurunkan nilai kinerja karyawan sebesar 0,871 .

Sedangkan hasil thitung budaya organisasi $\left(\mathrm{X}_{2}\right)$ nilainya sebesar 3,519, dengan memperhatikan nilai tabel pada alpha $(\alpha) 5 \%$ sebesar 1,9845 . Sehingga dapat dilihat nilai $t_{\text {hitung }}$ lebih besar dari tabel, dimana $(3,519>1,9845)$, menunjukkan $\mathrm{H}_{0}$ ditolak. Dengan demikian dapat disimpulkan bahwa variabel budaya organisasi mempengaruhi terhadap kinerja karyawan secara signifikan.

Analisis varian dengan memperhatikan signifikan uji $\mathrm{F}$ regresi bahwa pengaruh budaya organisasi $\left(\mathrm{X}_{1}\right)$ terhadap kinerja karyawan signifikan. Karena nilai $F_{\text {hitung }}$ yang nilainya sebesar 507,203 Sedangkan nilai $F_{\text {tabel }}$ pada alpha $(\alpha)$ 5\% sebesar 3,940. Sehingga dapat dipaparkan bahwa nilai $F_{\text {hitung }}$ lebih besar dari $F_{\text {tabel, dimana }}(507,203>3,940)$ yang berarti terjadi penolakan terhadap $\mathrm{H}_{0}$. Artinya variabel budaya organisasi mempengaruhi secara signifikan terhadap variabel kinerja karyawan, dan terdapat pengaruh nilainya dinyatakan sangat kuat. 
Disiplin Kerja dan Budaya Organisasi Secara Bersama-sama Terhadap Kinerja Karyawan. Hasil analisis regresi ganda dua prediktor antara disiplin kerja dan budaya organisasi terhadap kinerja karyawan menghasilkan $\mathrm{Y}=9,469+0,216\left(\mathrm{X}_{1}\right)+0,678\left(\mathrm{X}_{2}\right)$.

Tabel 6. Hasil uji koefisien Regresi $X_{1}$ dan $X_{2}$ Terhadap $Y$

Coefficients $^{\mathbf{a}}$

\begin{tabular}{|c|c|c|c|c|c|c|}
\hline & \multirow[t]{2}{*}{ Model } & Unstanda & Coefficients & \multirow{2}{*}{$\begin{array}{c}\begin{array}{c}\text { Standardized } \\
\text { Coefficients }\end{array} \\
\text { Beta }\end{array}$} & \multirow[t]{2}{*}{$\mathrm{T}$} & \multirow[t]{2}{*}{ Sig } \\
\hline & & $\mathrm{B}$ & Std. Error & & & \\
\hline \multirow[t]{3}{*}{1} & (Constant) & 9.469 & 3.253 & & 2.911 & 0.004 \\
\hline & Disiplin Kerja & .216 & .093 & .222 & 2.314 & 0.023 \\
\hline & $\begin{array}{l}\text { Budaya } \\
\text { Organisasi }\end{array}$ & .678 & .091 & .713 & 7.420 & 0.000 \\
\hline
\end{tabular}

a. Dependent Variable: Kinerja_Karyawan

Nilai t table pada alpha 5\%, df $1=99-1$ adalah 1.671

Nilai $r$ table pada alpha $5 \%, \mathrm{~N}=100$ adalah 0.195

Dari Tabel 6 hasil analisis antara disiplin kerja $\left(\mathrm{X}_{1}\right)$ dan budaya organisasi $\left(\mathrm{X}_{2}\right)$ terhadap kinerja karyawan (Y), Nilai konstanta sebesar 9,469 menyatakan bahwa jika tidak ada disiplin kerja dan budaya organisasi, maka kinerja karyawan sebesar 9,469.

Sedangkan hasil thitung Disiplin Kerja $\left(\mathrm{X}_{1}\right)$ dan Budaya Organisasi $\left(\mathrm{X}_{2}\right)$ secara bersama-sama nilainya sebesar 2,911, > nilai table pada alpha $(\alpha) 5 \%$ sebesar 1,9845 . menunjukkan $\mathrm{H}_{0}$ ditolak. Dengan demikian dapat disimpulkan bahwa variabel disiplin kerja dan budaya organisasi secara bersama-sama mempengaruhi terhadap kinerja karyawan secara signifikan.

Analisis varian dengan nilai signifikan uji F regresi, bahwa pengaruh disiplin kerja $\left(\mathrm{X}_{1}\right)$ terhadap kinerja karyawan signifikan. Hal ini dapat dilihat dari nilai $\mathrm{F}_{\text {hitung }}$ lebih besar dari $\mathrm{F}_{\text {tabel}}$, dimana $(267,551>3,940)$ yang berarti terjadi penolakan terhadap $\mathrm{H}_{0}$. Artinya variabel disiplin kerja dan budaya organisasi secara bersama-sama mempengaruhi secara signifikan terhadap variabel kinerja karyawan, dan terdapat pengaruh nilainya dinyatakan sangat kuat.

Analisis Pengujian Korelasi. Disiplin Kerja Terhadap Kinerja Karyawan. Berdasarkan hasil perhitungan diperoleh koefisien korelasi antara disiplin kerja terhadap kinerja karyawan. Hasil perhitungan keberartian koefisien tersebut (Tabel 7).

Berdasarakn Tabel 7 bahwa koefisien korelasinya $\mathrm{r}_{\text {hitung }}$ sebesar $0,871^{\mathrm{a}}$ Selanjutnya koefisien determinasi $\left(\mathrm{R}^{2}\right) 0.871=0,759^{\mathrm{a}}$ mengindikasikan bahwa faktor penentu sebesar $75,9 \%$ pengaruh yang diberikan oleh variabel disiplin kerja terhadap kinerja karyawan, sisanya $24,1 \%$ dipengaruhi oleh faktor-faktor lain diluar dari variabel penelitian ini.

Tabel 7. Hasil Uji Koefisien Korelasi $\mathrm{X}_{1}$ Terhadap Y

Model Summary ${ }^{b}$

\begin{tabular}{|c|c|c|c|c|c|c|c|c|c|c|}
\hline \multirow[b]{2}{*}{ Model } & \multirow[b]{2}{*}{$\mathrm{R}$} & \multirow{2}{*}{$\begin{array}{c}\mathrm{R} \\
\text { Square }\end{array}$} & \multirow{2}{*}{$\begin{array}{l}\text { Adjusted } \\
\text { R Square }\end{array}$} & \multirow{2}{*}{$\begin{array}{l}\text { Std. Error } \\
\text { of the } \\
\text { Estimate }\end{array}$} & \multicolumn{5}{|c|}{ Change Statistics } & \multirow{2}{*}{$\begin{array}{l}\text { Durbin- } \\
\text { Watson }\end{array}$} \\
\hline & & & & & $\begin{array}{c}\text { R Square } \\
\text { Change }\end{array}$ & $\begin{array}{c}\mathrm{F} \\
\text { Change }\end{array}$ & df1 & df2 & $\begin{array}{l}\text { Sig. F } \\
\text { Change }\end{array}$ & \\
\hline
\end{tabular}




\begin{tabular}{llllllllll}
\hline 1 & $.871^{\mathrm{a}}$ & .759 & .757 & 3.266 & .759309 .372 & 1 & 98 & .000 & 2.827
\end{tabular}

a. Predictors: (Constant), Disiplin_Kerja

b. Dependent Variable: Kinerja_Karyawan

Budaya Organisasi Terhadap Kinerja Karyawan. Berdasarkan hasil perhitungan diperoleh koefisien korelasi antara budaya organisasi terhadap kinerja karyawan. Hasil perhitungan keberartian koefisien (Tabel 8):

Tabel 8. Hasil Uji Koefisien Korelasi $\mathrm{X}_{2}$ Terhadap Y

Model Summary ${ }^{b}$

\begin{tabular}{|c|c|c|c|c|c|c|c|c|c|c|}
\hline \multirow[b]{2}{*}{ Model } & \multirow[b]{2}{*}{$\mathrm{R}$} & \multirow{2}{*}{$\begin{array}{c}\mathrm{R} \\
\text { Square }\end{array}$} & \multirow{2}{*}{$\begin{array}{l}\text { Adjusted } \\
\text { R Square }\end{array}$} & \multirow{2}{*}{$\begin{array}{l}\text { Std. Error } \\
\text { of the } \\
\text { Estimate }\end{array}$} & \multicolumn{5}{|c|}{ Change Statistics } & \multirow{2}{*}{$\begin{array}{l}\text { Durbin- } \\
\text { Watson }\end{array}$} \\
\hline & & & & & $\begin{array}{c}\text { R Square } \\
\text { Change }\end{array}$ & $\begin{array}{c}\text { F } \\
\text { Change }\end{array}$ & df1 & df2 & $\begin{array}{l}\text { Sig. F } \\
\text { Change }\end{array}$ & \\
\hline 1 & $.915^{\mathrm{a}}$ & .838 & .836 & 2.680 & .838 & 507.203 & 1 & 98 & .000 & 2.149 \\
\hline
\end{tabular}

a. Predictors: (Constant), Budaya_Organisasi

b. Dependent Variable: Kinerja_Karyawan

Dari Tabel 8 koefisien korelasinya $r_{\text {hitung }}$ sebesar $0,915^{\mathrm{a}}$ Selanjutnya koefisien determinasi $\left(R^{2}\right) 0.915=0,838^{a}$ mengindikasikan bahwa faktor penentu sebesar $83,8 \%$ pengaruh yang diberikan oleh variabel budaya organisasi terhadap kinerja karyawan, sisanya $16,2 \%$ dipengaruhi oleh faktor-faktor lain diluar dari variabel penelitian ini.

Disiplin Kerja dan Budaya Organisasi Secara Bersama-sama Terhadap Kinerja Karyawan. Berdasarkan hasil perhitungan diperoleh koefisien korelasi antara disiplin kerja dan budaya organisasi terhadap kinerja karyawan sebesar 0,920 dengan nilai $r$ tabel pada alpha ( $\alpha$ ) 5\% sebesar 0,195 . Uji signifikansinya dapat dilakukan dengan melihat nilai koefisien korelasi (ryx) (Tabel 9):

Dari Tabel 9 koefisien korelasinya $\mathrm{r}_{\text {hitung }} 0,920^{\mathrm{a}}>0,195$ sehingga $\mathrm{H}_{0}$ ditolak, artinya terdapat pengaruh antara disiplin kerja dan budaya organisasi secara bersama-sama terhadap kinerja karyawan. Selanjutnya koefisien determinasi $\left(R^{2}\right) 0,920^{a}=0,847$ mengindikasikan bahwa faktor penentu sebesar $84.7 \%$ pengaruh yang diberikan oleh variabel disiplin kerja dan budaya organisasi secara bersama-sama terhadap Kinerja Karyawan, sisanya $15,3 \%$ dipengaruhi oleh faktor-faktor lain diluar dari variabel penelitian ini.

Tabel 9. Hasil Uji Koefisien Korelasi $\mathrm{X}_{1}$ dan $\mathrm{X}_{2}$ Terhadap $\mathrm{Y}$

\begin{tabular}{|c|c|c|c|c|c|c|c|c|c|c|}
\hline & \multirow[b]{3}{*}{$\mathrm{R}$} & \multirow[b]{3}{*}{ R Square } & \multicolumn{7}{|c|}{ Model Summary $^{\text {b }}$} & \multirow{3}{*}{$\begin{array}{l}\text { Dur } \\
\text { - bin- } \\
\text { Wat } \\
\text { son }\end{array}$} \\
\hline \multirow[b]{2}{*}{ Model } & & & \multirow[b]{2}{*}{$\begin{array}{l}\text { Adjusted R } \\
\text { Square }\end{array}$} & \multirow[b]{2}{*}{$\begin{array}{l}\text { Std. Error of the } \\
\text { Estimate }\end{array}$} & \multicolumn{5}{|c|}{ Change Statistics } & \\
\hline & & & & & $\begin{array}{l}\text { R Square } \\
\text { Change }\end{array}$ & F Change & df1 & df 2 & $\begin{array}{l}\text { Sig. F } \\
\text { Change }\end{array}$ & \\
\hline 1 & $.920^{\mathrm{a}}$ & .847 & .843 & 2.622 & 047 & 967551 & & 97 & .000 & 2.507 \\
\hline
\end{tabular}


a. Predictors: (Constant), Disiplin_Kerja, Budaya_Organisasi

b. Dependent Variable: Kinerja_Karyawan

Nilai $\mathrm{r}$ table pada alpha $5 \%, \mathrm{~N}=100$ adalah 0.195

\section{PENUTUP}

Simpulan. Disiplin kerja berpengaruh positif terhadap kinerja karyawan, dengan nilai tingkat hubungan sangat kuat. Budaya organisasi berpengaruh positif terhadap kinerja karyawan, dengan nilai tingkat hubungan sangat kuat. Disiplin kerja dan budaya organisasi secara bersama-sama memiliki pengaruh positif terhadap kinerja karyawan. Berarti bahwa semakin baik disiplin kerja dan budaya organisasi, maka kinerja karyawan juga akan membuatnya semakin baik pula begitupun sebaliknya. Dengan demikian kinerja karyawan pada PT. Jasa Marga Tbk, cabang jagorawi secara signifikan sangat ditentukan secara bersama-sama oleh variabel disiplin kerja dan budaya organisasi.

\section{DAFTAR RUJUKAN}

Agrawal, A. (2013) Employee Development and Its Affect on Their Performance.

International Journal of Marketing, Financial Services and Management Research. 2(4). 2277-3622.http://indianresearchjournals.com/pdf/IJMFSMR/2013/April/9.pdf

Awad, Al Harby Mohammad dan Al Yahya Mohammad Saad. (2013) Impact of Organization Culture on Employee Performance. International Review Management Business Research. 2 (1). 168-175.

Blanchard K H, Zigami P,Zigami D. (1985) Leadership and the one minute manager, Increasing effectiveness through situational leadership, New York: Morrow Print.

Chirasha, Vonai. (2013) Management of Discipline for good Performance: A theoretical perspective. Online Journal of Social Sciences Research. ISSN 2277 - 0844, Volume 2, Issue 7, pp 214-219, July, 2013. http://onlineresearchjournals.org/JSS/pdf/2013/jul/Chirasha.pdf

Daft R L. (2000) Organization Theory and Design. 7th edition. South-Western College Publishing, Thomson Learning. U.S.A.

Dave Hofferberth dan Jeanne Urich. (2011) The Effect of Culture on Performance SPI Research,

Eric. (2010) On the origin of shared beliefs and corporate culture: The Rand Journal of Economics Vol.41, 617 - 648 .

Hameed, Waheed. (2011) Employee Development and It's Affect on Employee Performance A Conceptual Framework. International Journal of Business and Social Science. Vol 2. No13.

Henry. J, Afnan.E, Setiawan. M, dan Solimun. (2012) The Influence of Organizational Culture, Organizational Commitment to Job Satisfaction and Employee Performance (Study at Municipal Waterworks of Jayapura, Papua Indonesia): International Journal of Business and Management Invention. Volume 1 (1), 69-7.

Khorshidi, A. (2009) Management and Leadership Training (Second Edition), Tehran: Yastaroun Publications

Kotter, P. dan Heskett, L. (1992) Corporate Culture and Performance. New York: Macmillan 
Legowo, Fajar Wali Haryo., Rodhiyah., SU., Sari Listyorini. (2012) Pengaruh Kepuasan Kerja dan Disiplin Kerja Terhadap Prestas Kerja Pada CV. JM (Jaya Motor) SEMARANG. Jurnal Ilmu Administrasi Bisnis. nomor 1, Tahun 2012 > Legowo. http://ejournal-s1.undip.ac.id/index.php/jiab/article/view/841/816

Hasibuan, Malayu SP. (2007) Manajemen Sumber Daya Manusia, Jakarta: Bumi Aksara.

Jen-Te Yang. (2007) Knowledge sharing: Investigating appropriate leadership roles and collaborative culture. Journal Tourism Management. 28, 530-543

Mangkunegara, Anwar Prabu. (2001) Manajemen Sumber Daya Manusia Perusahaan, Bandung: PT Remaja Rosda Karya.

Monappa A. (2000) Management Challenges for the Corporations of Tomorrow, SAGE Publications. P. 161.

Mujeeb, Ehtesham Ul., Muhammad Tahir Masood., Muhammad Shakil Ahmad. (2011) Relationship between Organizational Culture and Performance Management Practices: A Case of University in Pakistan. Journal of Competitivenes. http://www.cjournal.cz/files/77.pdf

Nazir, Nadia dan Shazia Zamir. (2015) Impact of Organizational Culture on Employee's Performance. Industrial Engineering Letters. 5 (9). 31-37

Nongo.D dan Ikyanyon.D. (2012) The Influence of Corporate Culture on Employee Commitment to the Organization: International Journal of Business and Management. Vol. 7, No. 22.

Ogbonna, E. dan Harris, L. (2000) Leadership style, organizational culture and performance: Empirical evidence from UK companies. International Journal of Human Resources Management, 11(4), 766-788.

Rousseau, D. (1991) Quantitative assessment of organizational culture. Group and Organizations Studies, 15(4), 448-460.

Schein, E. H. (1996) The Role of the Founder in Creating Organizational Culture, The Leader of the Future, San fransisco: Jossey Bass.

Siagian, Sondang P. (2007) Teori Pengembangan Organisasi. Jakarta: Bumi Aksara

Santoso, Singgih. (2015) Menguasai SPSS 22, From Basic To Expert Skills. Jakarta: Elek Media Komputindo

Syirodj, Muhammad dan Aurik Gustomo. (2014) Analysis Of Corporate Leadership Culture Internalizationingroupedanone Indonesia Head Office. Journal Of Business And Management. 3. (7)., 718-724.

Wairimu, Lysiah Wambugu. (2014) Effects of Organizational Culture on Employee Performance (Case Study of Wartsila - Kipevu Ii Power Plant). European Journal of Business and Management. www.iiste.org ISSN 2222-1905 Vol.6, No.32.

Wirawan. (2009) Evaluasi Kinerja Sumber Daya Manusia Teori, Aplikasi, dan Penelitian. Jakarta: Salemba Empat. 